\title{
Marketing Digital e a Rede Social Facebook nos Serviços Turísticos: uma investigação sobre a interação entre os consumidores finais e a companhia aérea LATAM
}

\author{
Ada Lílian e Silva de Oliveira ${ }^{1}$; André Falcão Durão ${ }^{2}$; Carla Borba da Mota Silveira ${ }^{3}$
}

\begin{abstract}
Resumo: Nos últimos anos, em termos de possibilidades tecnológicas de comunicação, as redes sociais são quase onipresentes na vida das pessoas e ações estratégicas das empresas. Esta onipresença é fácil de observar na prestação de serviços turísticos. Neste cenário, o principal objetivo desta pesquisa foi analisar como a interação entre LATAM companhia aérea e os seus clientes através de sua página oficial na rede social Facebook. Os construtos marketing digital, redes sociais e uso redes sociais nos serviços de turismo deram suporte argumentativo teórico ao trabalho. Como procedimento metodológico, foram utilizados tendo em conta a abordagem qualitativa e interpretativa de pesquisa, a netnografia e observação não participante como uma maneira de explorar o comportamento dos consumidores on-line e conteúdo publicado por um período de seis meses. A partir da classificação de cargos da empresa e sua interação com os consumidores, os resultados indicam que o uso do Facebook como ferramenta de comunicação, promoção e relacionamento LATAM precisa ser melhorado. Há ainda benefícios potenciais significativos desta interação inexplorados. No entanto, existem aspectos positivos como respostas rápidas às demandas negativas dos usuários, como também o projeto de modernização de design da rede social e a promoção de vendas por impulso.
\end{abstract}

Palavras-chave: Marketing digital. Redes sociais. Facebook. LATAM. Serviços de viagens.

\section{Digital Marketing and Social Network Facebook in Tourism Services: A Interaction investigation between final users and LATAM airlines}

\begin{abstract}
Currently, regarding the technological possibilities for communication, social networks are almost omnipresent in people's lives and companies 'strategic actions. This omnipresence is easy to observe in the provision of tourist services. Therefore, the main objective of this research was to analyze how is the interaction between the airline LATAM and its consumers through its official page in the social network Facebook. The theoretical framework used as an argumentative support was digital marketing, social networks and the use of social networks in tourist services. As a methodological procedure, considering the qualitative and interpretive research approach, netnography and non-participant observation were performed to explore the online consumers' behavior and content published for a period of six months. Based on the categorization of the company's posts and its interaction with consumers, the results indicate that the use of Facebook as a communication, promotion and relationship tool LATAM needs to be improved. There are still significant potential benefits that need to be explored. However, there are positive aspects like quick responses to negative demands from users, modernization design and impulse sales promotion.
\end{abstract}

Keywords: Digital Marketing. Social Networks. Facebook. LATAM. Tourist Services

\footnotetext{
${ }^{1}$ Bacharel em Turismo pela Universidade Federal de Pernambuco. Contato: ada.lilian@ @otmail.com;

${ }^{2}$ Doutor em Administração. Bacharel em Turismo. Professor Adjunto do curso de Turismo da UFPE. Contato: afdurao@gmail.com;

${ }^{3}$ Doutora em Antropologia. Bacharel em Turismo. Professora Adjunta do curso de Turismo da UFPE. Contato: carla-borba@ uol.com.br. 


\section{Introdução}

O marketing está diretamente ligado à comunicação. As mensagens criadas podem ser transmitidas através de propagandas de rádios, na produção de programas de televisão; na mídia impressa, nas artes gráficas, nas páginas de revistas, entre outros.

$\mathrm{Na}$ internet não é diferente quanto à formulação de mensagens para o consumidor quando se trata de marketing. O ambiente virtual hoje é o mais fértil e crescente elemento para ações de marketing. Para Reino (2011, p.2), é ambiente de interação, onde as informações ficam disponíveis todo o tempo e as pessoas podem interagir e comentá-las. A comunicação virtual com o consumidor tem caráter obrigatório, dependendo de que segmento do mercado esteja sendo observado, como é o caso da atividade turística.

A internet possui um caráter extremamente prático, fluido, dinâmico. Os mundos online e off-line não são necessariamente realidades separadas - mundo real versus mundo virtual - mas podem ser consideradas um continuиm da mesma realidade (Noveli, 2010, p. 109). As redes sociais são o principal veículo de troca de informações no ambiente virutal. Elas integram perfis de usuários e comunidades geradas pelos próprios consumidores ou empresas, contribuindo com uma aproximação e sensação de estarem mais íntimos com todos que delas fazem parte.

A sua onipresença no mundo é revelada em números. Segundo pesquisa da agência global de marketing We Are Social, Digital in 2016 (2016), dos mais de sete bilhões de habitantes no planeta, pelo menos três bilhões e meio são usuários de internet. Destes, aproximadamente dois bilhões e meio são usuários ativos de redes sociais. Quando se observa um contexto acima descrito, parece lógico supor que esta mudança gerou reflexos diretos no mundo corporativo.

Para Baldan, Eras, Fedichina e Gozzi (2011, p. 1) as redes sociais podem contribuir para o fortalecimento da relação com clientes, o que tem feito com que as organizações tenham iniciado um processo de relacionamento e divulgação por meio das novas mídias.

A rede social Facebook, enquanto mídia de promoção corporativa, é uma das ferramentas que agrupa uma grande quantidade de membros e que constantemente pode sofrer atualizações. Cada vez mais a página do Facebook tenta fazer com que seus membros tenham 
a melhor experiência online a partir de seus costumes, tornando a utilização da comunidade mais prática e eficiente.

No universo das redes sociais, de acordo com Baldan et al. (2011, p. 5):

\begin{abstract}
Observa-se que mais do que um simples modismo, esta ferramenta pode tornar-se essencial para que o processo de relacionamento com o cliente torne-se vantagem competitiva. Dessa forma, as organizações que não estiverem preparadas para se adaptar a nova realidade poderão perder seu espaço e seus clientes.
\end{abstract}

O Facebook foi uma das primeiras mídias sociais que deu oportunidade para que desenvolvedores de software pudessem criar aplicativos que fossem utilizados pelos usuários. Essa oportunidade beneficia tanto os usuários como as empresas.

Em uma pesquisa realizada pela SocialBakers ${ }^{4}$ (2013), o Brasil já é o segundo país com mais usuários desta rede social. O potencial para alcance de consumidores por esta plataforma é extremamente relevante. A companhia aérea LATAM possui sua página corporativa no Facebook e é o objeto de estudo desta pesquisa.

No que diz respeito ao uso do ambiente virtual enquanto ferramenta de informação e tomadas de decisão de compra, uma pesquisa realizada pela $\operatorname{DraftFCB}^{5}$ (2011) concluiu que o consumidor brasileiro está dando mais importância às informações que são disponibilizadas online e que estas informações são influência uma compra, onde 19\% dos entrevistados são brasileiros "obcecados por informações".

Segundo a Agência CNT de Notícias ${ }^{6}$, em setembro de 2014, ocorreu um crescimento na demanda de transporte aéreo de passageiros, comparado com a mesma época em 2013. A LATAM liderou o mercado doméstico neste mesmo ano, com uma participação de $38,1 \%$. A taxa de aproveitamento das aeronaves utilizadas em voos domésticos operados por empresas brasileiras teve um recorde nos últimos dez anos e o número de passageiros pagos transportados atingiu 7,8 milhões, sendo o melhor mês da década.

Desta forma, esta pesquisa teve como objetivo analisar a interação entre consumidores finais e a empresa LATAM por meio de sua página corporativa no Facebook. A proposta da pesquisa foi refletir, a partir do objeto de estudo e dos resultados encontrados, sobre o uso de

\footnotetext{
${ }_{5}^{4}$ Empresa que oferece monitoramento e ferramentas de monitoramento para análise de redes sociais.

${ }^{5}$ Agência de Publicidade e Propaganda

${ }^{6}$ Confederação Nacional do Transporte 
redes sociais enquanto canais de comunicação e promoção organizacional como forma de fidelizar a demanda real e atrair potenciais consumidores.

\section{Marketing Digital}

Chaffey, Meyer, Johnston e Ellis-Chadwick (2003) definem o marketing digital como sendo o uso da internet e tecnologias digitais relacionadas para alcançar objetivos de marketing. Já para Kotler et al. (2009), compreendem como uma forma de comunicação e interação das organizações com os seus clientes, através de canais digitais (internet, e-mail, entre outros) e tecnologias digitais. Torres (2009) acredita que para conhecer literalmente o ambiente online e ter uma estratégia para o marketing digital, é necessário entender a rede como um todo e conseguir captar o que a sociedade online quer mostrar. Hoje, na internet, todas as classes sociais buscam informações, diversão e relacionamento. Ela interfere em qualquer atividade ligada à sociedade e aos negócios.

Reino (2010) afirma que o marketing digital é a aplicação dos conceitos de marketing no ambiente digital, principalmente na internet, maior rede de interconexão existente atualmente, enquanto para Oliveira, Lima, Baptista e Henrique (2012), o marketing digital são ações tomadas no ambiente virtual que visam promover um contato permanente entre uma empresa e o seu cliente. Os consumidores através do marketing digital devem tomar conhecimento da empresa, dos seus serviços, criar uma relação de confiança e formar uma tomada de decisão que favoreça a empresa de uma maneira que ela possa garantir seu desenvolvimento.

Segundo Park e Oh (2012), o marketing digital promove a imagem das empresas por meio de conteúdos, imagens, informações positivas nas mídias sociais, além de oferecer oportunidades para a rápida disseminação de informações através essencialmente da participação dos usuários. Para Yadav e Pavlov (2014), o marketing digital como uma prática de promover produtos e serviços através de distribuição em canais digitais.

Com a junção das mídias sociais e a internet na função de propagar uma mensagem, na atualidade, entende-se que o alcance de uma mensagem que foi compartilhada numa rede 
social pode ser inestimável e chegar até um público que até então não tinha conhecimento sobre o produto ou serviço.

Desta forma, as mídias digitais não funcionam apenas para a troca de mensagens instantâneas (ou não) com os amigos ou como uma aproximação entre familiares e colegas de trabalho. Reino (2010) argumenta que a grande força do marketing digital está na interatividade, na qual trata a exigência constante dos clientes e esta deve ser percebida como informação por meio dessa troca de dados que a internet utiliza.

Considerando que o consumidor é o ponto central da internet e baseando-se no seu comportamento, o conceito do comportamento do consumidor revela que as atividades básicas do comprador no ambiente virtual consistem no relacionamento, informação, comunicação e na diversão (Torres, 2009).

As redes sociais, enquanto uma das principais ferramentas do marketing digital, contribuem para uma relação mais estreita com o usuário; um relacionamento mais fortalecido que faz com que as empresas se mostrem mais em contato com seus clientes e promovam a disseminação da sua marca (Reino, 2010).

Florès (2012) e Hannah, Rohm e Crittenden (2011) acreditam que o marketing digital, o marketing do bem e o marketing de relacionamento são de suma importância, que se completam e são essenciais para a construção da relação cliente/empresa, buscando trazer para perto aqueles consumidores que estão a maior parte do tempo usando ferramentas tecnológicas, e na atualidade, o que está em evidência são as mídias sociais.

Diante desta realidade e considerando a forma como tem se comportado o usuário da internet que busca interagir de alguma forma com a atividade turística, as empresas ofertantes de produtos e serviços turísticos necessitam estar cada vez mais presentes no ambiente virtual de forma a se destacar frente à competição exacerbada que caracteriza o mercado do turismo. Explorar as possibilidades de comunicação, de promoção e de relacionamento com o consumidor em rede social como o Facebook é um dos primeiros passos. 


\section{Mídias Sociais e Redes Sociais}

Segundo Cruz, Mota e Perinotto (2012, p. 80) as redes sociais são constituídas de representações dos atores sociais e de suas conexões, interações. Essas representações são, geralmente, individualizadas e personalizadas. A abordagem de Safko e Brake (2010) complementa a primeira quando argumenta que estas interações são efetivadas através de aplicativos que possibilitam o diálogo - troca de palavras, vídeos, imagens e áudio - entre seus usuários.

Já Oliveira, Lima, Baptista e Henrique (2012, p. 7) trazem que "o internauta é muito mais que um mero consumidor" pelo fato dele participar e ser capaz de relatar sua experiência positiva ou negativa para que as outras pessoas possam ver e se sensibilizar.

A prática da comunicação nas redes sociais é o que a caracteriza como uma rede de relacionamento online, já que as redes sociais foram criadas para diminuir a distância entre grupos. Quando os recursos disponíveis e as propostas das redes sociais são os mais simples possíveis, facilita a participação dos usuários na troca de informações e outras maneiras de interagir que a página possa proporcionar.

Para Recuero (2009), o estudo das redes sociais foca o problema de como as estruturas sociais surgem, de que tipo são, como são compostas pela transmissão via computador e como essas interações são capazes de gerar informações e trocas sociais. As redes sociais possuem elementos com características fundamentais que se tornam a base da rede e das informações que ela propaga.

É possível que existam interações que visem somar e construir um determinado laço social e interações que tenham o objetivo de enfraquecer ou até mesmo destruir um laço (Recuero, 2009). Dessa maneira, as relações interpessoais como as relações empresa/cliente não são diferentes quando se trata de uma marca, que pode se fortificar ou se tornar debilitada.

Alves (2011) sugere que o aspecto básico de uma rede social é o ser humano, identificando que o centro da estrutura de um perfil numa rede é composto por pessoas, incluindo também o perfil de uma empresa. As redes sociais tornaram-se ferramentas que visam aumentar o conhecimento dos indivíduos, diminuindo a desconfiança, seja por outros usuários, ou até empresas (Alves, 2011, p. 57). As empresas, através das redes sociais, podem 
expandir sua presença online sem que exista um grande esforço financeiro, já que o uso dessas plataformas de comunicação ainda se encontra gratuito. A rede virtual possibilita inúmeras oportunidades de mercado.

Castells (2010) acredita que o papel da internet é importante por considerar que os utilizadores dela são pessoas jovens e mais qualificadas, e ainda atende para a importância de que isto não é um fator que comprometa as mídias tradicionais, mas que sejam uma contribuição para que mudanças sejam feitas nas práticas comunicacionais e de sociabilidade.

Segundo Cruz, Mota e Perinotto (2012), as redes sociais possuem uma grande influência, pois é um ambiente de convívio comum para os clientes potenciais dos serviços turísticos. Assim, no próximo tópico será explorada a situação das redes sociais do ponto de vista do turismo, trazendo a importância de seu uso e como afetam o setor.

\section{Redes Sociais e Serviços Turísticos}

A comunicação é de grande importância dentro de uma empresa, sendo vital para a organização e execução de suas tarefas. No Turismo a evolução dos meios de comunicação impactou desenvolvimento para a área. A comunicação entre as empresas e seus parceiros melhorou, bem como a comunicação com os consumidores.

Miguéns, Baggio e Costa (2008) dizem que as redes sociais estão alterando o modo como os turistas planejam suas viagens, permitindo uma maior interação por meio de opiniões sobre hotéis ou atrações turísticas locais. Isto é algo perceptível já que hoje existem plataformas dedicadas ao compartilhamento de experiências turísticas e assuntos de relevância para a área, como TripAdvisor e Foursquare, além de outros tipos de redes sociais e aplicativos.

O Facebook, além de uma ferramenta para consultas e reclamações, pode se tornar um elemento promocional eficiente, interagindo com o público por meio de promoções e compartilhamento de conteúdos exclusivos (Alves, 2011, p. 87). Dessa maneira, encontra-se praticidade na utilização de redes sociais para fins turísticos e de informações sobre destinos, serviços, curiosidades e um meio de aproximação com outras culturas, mesmo que de forma virtual. 
Alves (2011) considera que a utilização das redes sociais para fins de divulgação de produtos turísticos tem de ser encarada como mais uma alternativa no mercado. Existe um grande potencial na divulgação por parte desses meios de comunicação. Os usuários do site podem contribuir com detalhes adicionais sobre o produto/serviço, relatando sua experiência com ele. Esse tipo de participação, vinda dos utilizadores, chama a atenção tanto da empresa como de outras pessoas que possam estar lendo os comentários publicados na página.

Segundo Cruz, Mota e Perinotto (2012), a consolidação da internet como uma mídia de informação tem afetado o setor turístico e o comportamento dos consumidores, de modo tal que as empresas devem, imprescindivelmente, acompanhar as tendências virtuais e a evolução tecnológica que existem na atualidade.

O setor do turismo encontra-se cada vez mais vinculado às tecnologias de informação, devido à necessidade de agilizar os serviços, reduzir custos e melhorar o atendimento (Cruz, Mota \& Perinotto, 2012, p. 86).

Castells (2010) ressalta que a internet, como um todo, parece ser como uma fonte principal de influência na forma de consumo e comportamento da sociedade.

Flecha e Costa (2004) ressaltam que a interação do mercado dinâmico do turismo com as tendências virtuais e o setor do turismo reestruturado, acelerou o uso dos sites como um meio para o marketing, transação de produtos e serviços do turismo.

Para Cruz, Mota e Perinotto (2012), as redes sociais têm uma grande influência na escolha de um produto ou destino turístico por ser um ambiente em que há vários clientes potenciais.

A internet é uma forma de expansão rápida quando se trata de informações e no turismo, essa rapidez no envio de informações torna-se fundamental para seu crescimento. Cruz, Mota e Perinotto (2012) argumentam ainda que o setor turístico não funcionaria sem a internet, uma vez que o turista precisa obter informações antes de seguir com sua viagem.

Para Oliveira et al. (2012) as ações que são realizadas no Facebook são extraordinárias, pois a fácil utilização da ferramenta através de mensagens e comentários na página faz com que o relacionamento se forme mais rápido. Porém ainda existe uma carência de melhorias na eficiência da utilização dessas redes para o turismo, que segundo Cruz, Mota e Perinotto (2012), se ocorressem, poderiam reduzir custos, potencializar mais vendas e conquistar novos clientes. 
Novamente, o objetivo desta pesquisa é justamente analisar o uso do Facebook pela LATAM enquanto ferramenta de interação com seus consumidores.

\title{
Procedimentos Metodológicos
}

Para esta pesquisa, foi utilizada uma abordagem qualitativa, seguindo o argumento de que para que algo seja bem compreendido, deve-se ir até o objeto de estudo e procurar entendê-lo. Neste caso, o objeto de estudo é a interação entre os consumidores e a companhia LATAM, através de sua página corporativa no Facebook.

Como procedimento metodológico, foi escolhido o estudo de caso, que segundo Godoy (1995, p. 25) "é um tipo de pesquisa cujo objeto é uma unidade que se analisa profundamente".

Com as dimensões existentes em um estudo de caso e o objeto de estudo juntamente com suas características, esta pesquisa se caracteriza como um estudo de caso netnográfico. A netnografia, segundo Kozinets (2015), é a etnografia na internet, um método de pesquisa qualitativa que adapta técnicas de pesquisas etnográficas no estudo de culturas e comunidades através da comunicação mediada por computador.

Para Kozinets (2015, p. 115):

\begin{abstract}
A principal diferença entre a netnografia e sua percursora, a etnografia, seria que a primeira parte da observação do discurso textual no contexto online, e a identidade do informante nesse contexto é duvidosa; enquanto que a etnografia face a face, na qual as pessoas buscam apresentar uma autoimagem mais cuidadosamente cultivada e controlada. Assim, a etnografia estaria mais próxima devido ao encontro face a face, da interação e da observação de comportamentos, de uma autoimagem e de uma identidade mais autêntica.
\end{abstract}

Para a obtenção dos dados necessários para os resultados desta pesquisa, o trabalho de campo consistiu-se na inserção direta no local de estudo, tomando a observação nãoparticipante como ação principal na coleta, com base nos objetivos da pesquisa e seguindo-se uma rota de observação em que fosse possível perceber os acontecimentos e as publicações realizadas na página da LATAM Airlines online por um período de seis meses, entre agosto de 2014 a janeiro de 2015. 
Os resultados obtidos deram-se pela busca por um padrão de utilização por parte da página do Facebook da LATAM Airlines, como a quantidade de postagens realizadas, curtidas recebidas por cada post, número de comentários e respostas dadas pela equipe administradora do perfil no Facebook, de modo que fosse possível fazer um comparativo entre os meses.

Para a análise de conteúdo online, o paradigma utilizado foi o interpretativismo, que segundo Mabrouki (2014) pode ser visto como um construtivismo moderado. Ele defende a hipótese relativista que não se pode ter uma única representação da realidade. No entanto, esta abordagem enfatiza que o pesquisador pode ou não co-construir a realidade com os atores. Esta pesquisa assumiu uma postura interpretativista visto que seu intuito principal é a interpretação do que os elementos estudados no ambiente online representam e suas ações realizadas por meio da plataforma Facebook.

O conhecimento deve ser construído baseado no mundo em que se vive e por meio de uma descrição realizada pelo pesquisador. A netnografia foi utilizada como forma de identificar e analisar o comportamento destes usuários da página online, já que este método compreende a inserção do pesquisador por intermédio de equipamentos eletrônicos na investigação e observação de práticas de comunicação e práticas culturais dos indivíduos estudados.

\section{Resultados e Discussão}

Segundo sua página oficial no Facebook, a LATAM Airlines a desenvolveu com o intuito de compartilhar suas novidades com seus clientes, campanhas, ofertas e outros conteúdos que possam ser relevantes e que dizem respeito à LATAM. Durante o período da pesquisa, compreendido entre fim de julho, início de agosto de 2014 a janeiro de 2015, a companhia aérea fez um total de 292 postagens conforme mostrado na tabela 1: 
Tabela 1 - Número de Postagens por Mês

\begin{tabular}{c|c}
\hline Julho / Agosto & 53 \\
Setembro & 52 \\
Outubro & 44 \\
Novembro & 56 \\
Dezembro & 46 \\
Janeiro & 41 \\
Total & $\mathbf{2 9 2}$ \\
\hline Fonte: Elaborado pelos autores (2015)
\end{tabular}

Conforme mostrado na tabela 1, identificam-se postagens não regulares, mas que tentam manter uma média mensal estabelecendo-se entre quarenta e sessenta postagens. As postagens são feitas diariamente, ocorrendo entre uma ou duas vezes por dia com uma frequência maior entre o período da tarde e da noite, exceto nos finais de semana, onde são postadas apenas uma vez com horário geralmente por volta das $10 \mathrm{~h}$ e $15 \mathrm{~h}$.

Cruz, Mota e Perinotto (2012) afirmam que a circulação das postagens significa que houve um aumento de pessoas que podem ter acesso aos conteúdos, imagens e até mesmo vídeos que são publicados na página. Se houvesse mais quantidade de publicações diárias, provavelmente estas publicações teriam mais curtidas e se tornariam mais populares por estarem em evidência no feed de notícias dos utilizadores do Facebook.

O significado de curtir é uma maneira fácil de expressar a quem postou o conteúdo, que o usuário gostou da postagem sem necessariamente ter que deixar um comentário. As curtidas que acontecem na página da LATAM estão relacionadas ao horário e o conteúdo da postagem, sendo algo que chame atenção do leitor. A página oficial da LATAM no Facebook teve um total de 685.876 curtidas ao longo dos seis meses de pesquisa em suas postagens totais mensais. Na tabela dois, é possível ver o quantitativo de curtidas que a página teve referente a estas postagens mensais: 
Tabela 2 - Número de Curtidas Recebidas nas Postagens por Mês

\begin{tabular}{c|c}
\hline Julho/ Agosto & 112.084 \\
Setembro & 147.670 \\
Outubro & 80.891 \\
Novembro & 87.161 \\
Dezembro & 86.626 \\
Janeiro & 171.444 \\
Total & $\mathbf{6 8 5 . 8 7 6}$ \\
\hline Fonte: Elaborado pelos autores (2015)
\end{tabular}

Provavelmente a oscilação identificada na tabela dois tenha ocorrido por conta do período de férias, visto que as pessoas estão se preparando para viajar e estão atentas às informações que são publicadas pela companhia aérea na rede social.

As curtidas que a página da LATAM recebe em suas publicações estão relacionadas ao tipo de conteúdo que a página da empresa coloca online. A partir da observação na página virtual e as características do conteúdo postado, categorias destas postagens foram criadas durante o período da pesquisa. A seguir apresenta-se a tabela três com estas categorias, como também a quantidade, além da discussão de algumas delas:

Tabela 3 - Categorias e Quantidade de Conteúdo Postado

\begin{tabular}{c|c}
\hline Curiosidades & 6 \\
Informes sobre a TAM & 38 \\
Museu TAM & 7 \\
\#TAMFace & 90 \\
Vídeos & 9 \\
Promoções & 8 \\
Multiplus & 3 \\
Dicas Sobre Destinos & 45 \\
Ampliando Seu Mundo & 48 \\
Outros Conteúdos & 34 \\
Total & $\mathbf{2 8 8}$ \\
\hline Fonte: Elaborado pelos autores (2015) &
\end{tabular}


Foram observadas trinta e oito postagens na linha do tempo que remeteram ao qualquer tipo de comunicado da LATAM, estes que incluem notícias sobre novas aeronaves, novas salas de embarque em aeroportos, orientações para despacho de bagagens, entre outros comunicados. Essas publicações são importantes para os clientes que acessam a página, pois conseguem manter o consumidor atento ao que está acontecendo com a empresa, além de obter informações gerais sobre serviços sem ter que acessar o site oficial da companhia aérea, o que corrobora com os argumentos de Reino (2011), Hannah, Rohm e Crittenden (2011) e Florès (2012).

A LATAM teve em sua página apenas oito publicações dedicadas ao anúncio de promoções durante a pesquisa, algo que pode ser considerado um número baixo visto que uma página na rede social pode ter um grande alcance em se tratando de clientes potenciais. Três das publicações feitas sobre promoções garantiram três dos quatro maiores números de curtidas entre os seis meses estudados, sendo o primeiro com 51.834, a segunda com 42.941 e a terceira publicação com 39.397 curtidas.

Como a própria página da LATAM já havia indicado em sua descrição que tinha como proposta publicar conteúdo diversificado, durante a pesquisa percebeu-se que a maioria deste conteúdo variava entre imagens de aeronaves e fotos de destinos que combinavam frases de efeito. Postagens de imagens de aeronaves parecem não ter efeito na construção de relacionamento, dependendo do que se diz com a imagem. Já a imagem de destinos tem um apelo maior, mas é preciso uma junção com a mensagem escrita para maximizar seu efeito. Consumidores desejam não apenas boas experiências, mas que estas possuam informação útil, constatação congruente com as argumentações de Alvez (2011).

Percebeu-se também que as publicações relacionadas ao envio de fotos de clientes tornaram-se bastante comuns por ser uma maneira de fazer com que os viajantes, de certa forma, popularizassem a marca da empresa e ainda divulgassem um destino que a companhia aérea foi capaz de fazer o elo de chegada/partida. Estas ações estão em consonância com os preceitos e argumentos de Safko e Brake (2010) e Cruz, Mota e Perinotto (2012), ao considerarem as redes sociais como um espaço de representações sociais e suas conexões e interações, que possibilitam formas de diálogos por meio de troca de palavras, vídeos, imagens e áudios. 
Durante a pesquisa, houve uma mudança de layout na página da empresa. Foi um ponto importante no desenvolvimento da página como uma referência online. $\mathrm{O}$ visual que um produto tem muitas vezes atrai o consumidor. Kotler e Keller (2012, p. 371) definiram o design como o conjunto de características que afetam a aparência e o funcionamento do produto em termos de exigências do cliente e também consideram que os consumidores reagem de maneiras diferentes a imagem de diferentes empresas e marcas. A reação dos consumidores da LATAM foi extremamente positiva.

Na grande maioria das publicações feitas pela LATAM, os comentários recebidos vão desde os que enaltecem a empresa até comentários que relatam acontecimentos inusitados e sobre experiências ruins com os serviços da LATAM. No geral, a TAM recebeu durante seis meses, um total de 39.986 comentários.

Algumas vezes os comentários deixados na página da LATAM são dúvidas, elogios e reclamações. Embora a LATAM faça o possível para responder a todas as pessoas que comentam suas publicações, percebeu-se que o tempo de resposta está ligado à gravidade do comentário e também com base no que a empresa pode resolver de imediato. Comentários dos consumidores que são, de certa forma, "escolhidos" para um feedback demonstram incongruência entre o que se promove e o que se faz em termos de interatividade, apesar da repercussão positiva dos usuários toda vez que a empresa resolvia um problema postado em sua página.

Muitas vezes o que define o diferencial encontrado nos comentários existentes na página é que este parece ser o reflexo de um serviço que a empresa ofereceu. Pelo menos online, a LATAM mostrou preocupação e interesse em ajudar as pessoas que publicaram relatos ruins e históricos não muito positivos com a empresa, ao mesmo tempo em que também agradeceu (com menos frequência) àqueles que mostraram confiança e deram credibilidade aos serviços e oportunidades que a TAM proporcionou. 


\section{Considerações Finais}

Após a análise dos resultados, conclui-se que a LATAM possui uma diversidade de publicações, procurando informar de maneira mais interativa possível os internautas e tentando não ser apenas uma página formal.

Embora tenha componentes que contribuam para a criação de um vínculo, ainda há uma carência na quantidade de publicações visto que a média atual é de apenas uma postagem por dia. É um número baixo em se tratando de conseguir um bom reconhecimento e atingir clientes potenciais, por mais que as postagens venham acompanhadas de grandes números.

No início da pesquisa a LATAM possuía um layout diferente do atual em suas postagens. A maneira como modificaram a estrutura dessas publicações com certeza trouxe mais credibilidade e aspecto de organização na página.

A publicação de materiais que continham uma mensagem mais próxima de um diálogo entre pessoas do "mundo real", por exemplo, conseguiu mostrar que a empresa procurou deixar claro que deseja ter um contato mais próximo com os clientes.

Mais do que um meio de venda de seus serviços, deixar claro que a empresa está fazendo parte do dia-a-dia das pessoas. Esta "atitude" parece fomentar e fortalecer relacionamentos sólidos.

O cliente que visita e comenta atualmente a página do Facebook da LATAM, em sua grande maioria, é aquele que está buscando mostrar à empresa sua insatisfação, pondo em questão situações que se tornaram um grande incômodo e que gostariam de ter seus problemas solucionados. Menos presentes, mas não menos relevantes, estão os clientes que gostam de mostrar o motivo pelo qual escolheram a companhia aérea como sua preferida. Isso demonstra a importância de uma rede social como ferramenta de recuperação de serviço. As soluções dadas pela empresa nos casos de insatisfação teve ótima repercussão.

Desta forma, a influência que a página da LATAM no Facebook pode trazer aos consumidores de seus serviços é que graças à junção dos novos hábitos de consumo feitos online e aos serviços tecnológicos, os vínculos criados entre uma empresa/cliente podem ser expressivos, já que o consumidor atual encontra-se muito mais maduro e exigente, utilizando as redes sociais para pesquisar e se expressar sobre algo. 
Percebe-se que a LATAM, tendo como base a teoria exposta, ainda encontra-se caminhando para tornar a sua página na rede social Facebook efetiva em termos de promoção de seu produto e implicações em vendas reais.

Sugere-se para estudos futuros, a análise do real impacto da utilização de uma rede social como o Facebook no comportamento do consumidor, tendo este último como foco do estudo. Além disso, estudos comparativos entre as empresas do mesmo setor podem ser extremamente relevantes para que seus gestores percebam suas forças e fraquezas no uso de mídias sócias como ferramentas de promoção, comunicação e relacionamento com o consumidor. Por fim, estudos prospectando novas redes sociais, bem como comparando as características e efeitos de redes sociais consolidadas como o Twiter, Instagram e o Facebook.

\section{Referências}

ALVES, M. M. (2011). O Papel das redes sociais no turismo: Uma análise da situação das agências de turismo no Distrito Federal. Dissertação de Mestrado, Universidade de Brasília, Distrito Federal, DF.

BALDAN, A. K., ERAS, A.L., FEDICHINA, M.A.H., GOZZI, S. (2011, outubro). A Estratégia de Relacionamento com o Cliente por meio das Redes Sociais. Anais do XIV Seminários em Administração, São Paulo, SP, Brasil.

CASTELLS, Manuel. (2010). A sociedade em rede. São Paulo: Paz e Terra.

CHAFFEY, DAVE; MAYER, RICHARD; JOHNSTON, KEVIN; ELLIS-CHADWICK, FIONA. (2003). Internet Marketing: Strategy, Implementation and Practice. Harlow: Financial Times Prentice Hall.

CRUZ, V.L., MOTA, K. M., PERINOTTO, A. R. C. (2012). Redes sociais na internet: Estratégia para divulgação das potencialidades turística do Piauí-Brasil. Rosa dos Ventos, 4 (1), 77-88.

ESTADO, Agência. (2014). Transporte aéreo doméstico e internacional é o maior em 10 anos no Brasil. Recuperado em 14 de dezembro de 2014 de http://www.diariodepernambuco.com.br/app/noticia/economia/2014/10/15/internas_economia ,536292/transporte-aereo-domestico-e-internacional-e-o-maior-em-10-anos-no-brasil.shtml.

DIGITAL in 2016 (2016). We are Social Compendium of Global Digital, Social, and Mobile Data, Trends, and Statistics. Retrieved in July 30th from http://wearesocial.com/specialreports/digital-in-2016. 
FLECHA, A., COSTA, J. P. (2004). O impacto das novas tecnologias nos canais d distribuição turística: Um estudo de caso em agência de viagens. Caderno Virtual de Turismo, 4(4), 44-56.

FLORÈS, Laurent. (2012) Mesurer l'efficacité du marketing digital: Estimer le ROI pour optimiser ses actions. Paris: Dunod.

GODOY, A. (1995). Pesquisa Qualitativa: Tipos Fundamentais. Revista de Administração de Empresas, 35(3), p.20-29.

HANNA, R.,ROHM, A.,CRITTENDEN, V.L. (2011). We're all connected: The power of the social media ecosystem. Business Horizons, 54 (3), 265-273.

KOTLER, PHILIP; KELLER, KEVIN L.; BRADY, MAIRED; GOODMAN, MALCOLM; HANSEN; TORBEN. (2009). Marketing Management. Harlow: Pearson Education Limited.

KOTLER, P., KELLER, K. L. (2012). Administração de Marketing. São Paulo: Prentice Hall.

KOZINETS, R.V. (2015). Netnography: redifined. 2.ed. Londres, UK. Sage.

LIMEIRA, Tania. E-marketing: O marketing na internet com casos brasileiros. São Paulo: Saraiva, 2007.

MABROUKI, N. E. (2014). Méthodologie de recherche:Regard épistémologique. Recuperado em 06 de fevereiro de 2015, de http://economia.ma/fr/bg/nabil-elmabrouki/methodologie-de-recherche-regard-epistemologique-1.

MIGUÉNS, J.; BAGGIO, R.; COSTA, C. (2008). Social media and Tourism Destinations: TripAdvisor Case Study. Recuperado em 13 de dezembro de 2014, de http://www.iby.it/turismo/papers/baggio-aveiro2.pdf.

MINISTÉRIO do Turismo. (2014). A importância da internet para o turismo: Viajantes se apoiam nas redes sociais para decidir o roteiro, organizar a viagem e compartilhar informações. Recuperado em 16 de dezembro de 2014, de http://www.turismo.gov.br/turismo/noticias/todas_noticias/20140428.html.

OLIVEIRA, P.C., LIMA, R.V., BAPTISTA, J.A.A, HENRIQUE, M.R. (2012, junho). A utilização das redes sociais em empresas de pequeno porte da cidade de São Paulo. Anais do VII Congresso Nacional em Excelência em Gestão. Rio de Janeiro, RJ, Brasil.

PARK, J., OH, I.K. (2012). A case study of social media marketing by travel agency: the salience of social media marketing in tourism industry. International Journal of Tourism Sciences. 12(1), 93-106. 
Id on Line Revista Multidisciplinar e de Psicoloqia

Id on Line Multidisciplinary and Psycology Journal

TORRES, C. (2009). A Bíblia do Marketing: Tudo o que você queria saber sobre marketing e publicidade na internet e não tinha a quem perguntar. São Paulo: Novatec.

RECUERO, R. (2009). Redes Sociais na Internet. Porto Alegre: Meridional.

REINO, L. S. A. (2010). Redes Sociais e Marketing Digital, o Caso do Firula's Café. Recuperado em 30 de setembro de 2014 de http://www.bocc.ubi.pt/.

SAFKO, L., BRAKE, D.K. (2010). A Bíblia da Mídia Social: táticas, ferramentas e estratégias para construir e transformar negócios. São Paulo: Blucher.

YADAV, MANJIT S., PAVLOU, PAUL A. (2014). Marketing in Computer-Mediated Environments: Research Synthesis and New Directions. Journal of Marketing: January 2014, Vol. 78, No. 1, pp. 20-40. doi: http://dx.doi.org/10.1509/jm.12.0020 .

Como citar este artigo (Formato ABNT):

OLIVEIRA, Ada L. e S.; DURÃO, André F.; SILVEIRA, Carla Borba da Mota. Marketing Digital e a Rede Social Facebook nos Serviços Turísticos: uma investigação sobre a interação entre os consumidores finais e a companhia aérea LATAM . Id on Line Revista Multidisciplinar e de Psicologia, 2017, vol.11, n.37, p.178195. ISSN: 1981-1179.

Recebido: 02.08.2017

Aceito: 17.08 .2017 